\title{
Priscilla Horton, la ninfa de cabellos dorados: una actriz convertida en gerente teatral en el Londres victoriano ${ }^{2}$
}

\author{
Pricilla Horton, the Nymph with the Golden Locks: An \\ Actress Turned Theatre Manageress in Victorian London
}

\begin{abstract}
RESUMEN
En este artículo repasamos la vida de Priscilla Horton (1818-1895), actriz y gerente de teatro del siglo xIX más conocida como Mrs. German Reed. A menudo olvidada en los volúmenes dedicados al estudio del teatro victoriano, su trayectoria nos permite descubrir la situación social de las actrices de la época y las dificultades a las que debían hacer frente. Sin embargo, a diferencia de muchas otras, Horton disfrutó del favor de sus contemporáneos gracias a su talento sobre los escenarios. Además, su matrimonio con Thomas German Reed (1817-1888) y la posterior creación del Gallery of Illustration en Regent Street, Londres, le otorgó un nuevo estatus de patrona de las artes y de mujer refinada. Junto a su marido, Horton impulsó un nuevo género a mediados del siglo XIx, el «entretenimiento de salón» o drawing-room entertainment, atrayendo incluso a la élite que consideraba el teatro como vulgar e inmoral.
\end{abstract}

Palabras clave: Priscilla Horton, Mrs. German Reed, actriz victoriana, teatro inglés victoriano, entretenimiento de salón.

\section{Abstract}

In this article, I scrutinize the life of Priscilla Horton (1818-1895), a nineteenth-century actress and theatre manageress, better known as Mrs. German Reed. Oftentimes forgotten in the volumes dedicated to the study of Victorian theatre, her career in the theatre scene exemplifies the social situation of the actresses of the time and the difficulties they faced. However, unlike many others, Horton enjoyed the favor of her contemporaries thanks to her talent on stage. Moreover, her marriage to Thomas German Reed (1817-1888) and the establishment of the Gallery of Illustration in Regent Street, London, endowed her with a newfound status of patroness of arts and refined woman. Next to her husband, Horton promoted a new dramatic genre in the mid-nineteenth century: the drawing-room entertainment. In the end, the Reeds' establishment made theatre popular amongst the elite circles who claimed that theatergoing was sinful and immoral.

Keywords: Priscilla Horton, Mrs. German Reed, Victorian actress, Victorian English theatre, drawing-room entertainment.

1 Universitat de València, mapute@alumni.uv.es

2 El siguiente artículo se enmarca dentro del Proyecto de Investigación financiado por el Ministerio de Economía y Competitividad 'Orientation': Una perspectiva dinámica sobre la ficción y la cultura contemporáneas (1990-en adelante) (Ref: FFI2017-86417-P), dirigido por la Dra. Rosario Arias Doblas (Universidad de Málaga), y del Grupo de Investigación de la Universidad de Valencia Literature, Arts and Performance (Ref: GIUV2017-354), dirigido por la Dra. Laura Monrós Gaspar (Universitat de València). 


\section{SUMARIO}

1.- Introducción. 2.- La reputación de la actriz como objeto erótico y sobrenatural. 3.- La transformación de la actriz: de Priscilla Horton a Mrs. German Reed. 4.- Conclusión. -Referencias bibliográficas.

\section{Introducción}

Para poder introducir la figura de Priscilla Horton (1818-1895), conocida en sus últimos años como Mrs. German Reed, debemos mirar atrás y comprender el contexto social y teatral del Londres del siglo xIx. Su trayectoria de vida ejemplifica la de otras actrices victorianas que supieron crecer en su profesión y llegaron a dirigir algunos de los teatros más importantes de Londres. Estas mujeres, las wo-managers $^{3}$, generalmente habían tenido la ventaja de nacer dentro del seno de familias dedicadas al mundo del teatro, facilitando así su camino en el mundo profesional. Durante el siglo xIX, la entrada de las mujeres a la industria se vio dificultada, entre otras cosas, por los códigos morales. Sin embargo, el entorno teatral se convirtió en uno de los pocos ámbitos accesibles para ellas, llegando a ser cientos de ellas las encargadas de administrar locales y espectáculos (Davis, 2000: 273). Casi siempre, las wo-managers debían escalar puestos antes de convertirse en patronas de teatros, empezando desde el coro de bailarinas y mejorando su repertorio con los años.

A pesar de la oportunidad que el mundo de la interpretación les brindaba, debido a la controversia en torno a la actriz y a su papel activo en la esfera pública, este trabajo no era considerado «decente» para las mujeres de clase media-alta. Michael R. Booth (1991: 113) explica cómo las mujeres procedentes de las clases sociales más bajas aspiraban a alcanzar la fama en el teatro, ya que generalmente estas no sufrían el rechazo de sus familias al hacerlo. Esto se debía principalmente a que las expectativas de ingresos de una buena actriz podían ser muy altas y su éxito podía significar el enriquecimiento -y enaltecimiento- de toda una familia.

Así, a pesar de la condena social a la que a menudo se veían sujetas, muchas mujeres buscaron la liberación de sus cuerpos en el teatro. Las actrices de la época representan a unas pocas mujeres que alcanzaron la fama en un ámbito previamente reservado para el hombre, usando sus voces y viviendo gracias a su trabajo durante una época en la que las mujeres trabajadoras resultaban incómodas para muchos. La escena teatral del Londres victoriano está plagada de ejemplos de mujeres que, en menor o mayor medida, fueron capaces de «sacar provecho» de sus cuerpos a través de su profesión como actrices.

Dora Jordan (1761-1816) y Sarah Siddons (1755-1831) sientan las bases para sus sucesoras victorianas; y es que ambas fueron famosas por gozar del respeto y la fascina-

3 El término wo-manager es utilizado por primera vez por Tracy C. Davis (2000: 284). Según Davis, esta palabra crea un híbrido de dos conceptos previamente incompatibles, ya que el mundo profesional de la Inglaterra del siglo xix solía estar reservado a hombres. En su capítulo en el volumen de Davis y Donkin (1999: 99-124), Jane Moody explica la idoneidad de las mujeres para tomar las riendas de los recintos teatrales de la época y equipara a la gerente teatral a una ama de casa «cuidando» del «hogar» teatral. 
ción del público, llegando a codearse con la élite intelectual y social de su tiempo ${ }^{4}$. Las vidas de estas mujeres eran muy públicas y muy comentadas entre los círculos ajenos al teatro, provocando así que se convirtieran en modelos a seguir de muchas chicas de clase baja que soñaban con dejar atrás vidas de reclusión en el hogar paternal, matrimonios no deseados o incluso trabajos mal pagados para poder mantener a sus familias ${ }^{5}$.

Posteriormente, a lo largo del siglo XIX, la figura de la actriz se convirtió en una contradicción de atracción y repulsión a la vez. Quizá, y entre otras razones, los emergentes movimientos feministas victorianos fueran parte de la causa. Siguiendo el puritanismo religioso de la época, las mujeres fueron colocadas en un «pedestal» metafórico, desde el cual debían servir como ejemplo de superioridad moral y de candidez. Al principio, el movimiento feminista decimonónico hizo alarde de esta superioridad con tal de impulsar los derechos de las mujeres en el ámbito doméstico. Poco a poco, estos grupos se convirtieron en activismo político y se pidieron mejoras en los ámbitos de la educación, la política, el trabajo, la industria y el matrimonio. Entre los primeros círculos feministas de Inglaterra se encuentra el Langham Place, fundado en Londres alrededor de 1850 y el cual contaba con el trabajo de importantes mujeres como Barbara Bodichon, Bessie Parkes, Octavia Hill, y Elizabeth Garrett, entre otras ${ }^{6}$. Mediante la creación de revistas como el English Woman's Journal (1858-1864), lo que muchos consideraban un movimiento feminista desestructurado empezó a convertirse en grupos activos y organizados que reivindicaban los derechos de las mujeres. Cuando más tarde, a finales del siglo XIX y principios del XX, el movimiento sufragista llega a su punto álgido, se crearon grupos de apoyo en el ámbito teatral. Este es el caso del Theatrical Ladies Guild, fundado en 1891 por unas sesenta actrices, cuyo objetivo era ayudar a actrices desamparadas y a sus hijos; unos años después, en 1908, actrices afamadas como Ellen Terry, Cicely Hamilton y Lillie Langtry fundaron la Actresses' Franchise League, mediante la cual se promovió el movimiento sufragista e incluso se realizaron obras de teatro sobre los derechos de las mujeres ${ }^{7}$.

Sin embargo, a pesar de que la emancipación de la mujer pasó a ser uno de los temas candentes de la segunda mitad del siglo XIX, los medios seguían intentado restar credi-

4 Dora Jordan (1761-1816) fue famosa por su relación con el rey Guillermo IV en el siglo XVIII, con quien tuvo diez hijos ilegítimos. Sarah Siddons (1755-1831), procedente de una familia de actores, fue conocida por sus papeles trágicos de principios del siglo xIx. Otras, como la francesa Sarah Bernhardt -quien fue alabada por Oscar Wilde- y la italiana Eleonora Duse, gozaron de fama mundial. En Inglaterra, Ellen Terry (1847-1928), descendiente de una familia de actores, se convirtió en musa de poetas y pintores -como su primer marido George Frederic Watts-, y se la relacionó con el primer ministro W. E. Gladstone.

5 Mary Lyndon Shanley (1989: 10) identifica seis trabajos -mal pagados- que las mujeres de clase media podían desempeñar durante el siglo xIx: institutriz, profesora, dependienta, enfermera, administrativa y funcionaria pública.

6 Phillipa Levine (1987) examina con detalle el movimiento feminista del siglo xIx y establece al Langham Place como uno de los primeros en iniciar comités de campaña y en ofrecer bibliotecas y salas de estudio para mujeres. En definitiva, el Langham Place otorgó a las mujeres un entorno propio en el West End londinense en el que poder debatir su situación social y política.

7 Estas obras eran escritas por las mismas mujeres que formaban parte de la Actresses' Franchise League. Algunos ejemplos son Votes for Women (1907) de Elizabeth Robins, Pageant of Great Women (1909) y The First Actress (1911) de Cicely Hamilton (Clark, 2008: 120). 
bilidad a estas mujeres trabajadoras, especialmente a las actrices. A través de caricaturas, fotografías y críticas plagadas de dobles sentidos atacando su moralidad, los cuerpos y la identidad de las mujeres dedicadas al teatro pasaron a ser casi de dominio público. Con la popularización del teatro y del medio visual -fotografías y dibujos inclusive-, el cuerpo femenino fue empleado con connotaciones eróticas para desacreditarla. La ilustración erótica llegó incluso a algunos anticuarios del centro londinense, en los que se podían comprar desde libros antiguos a litografías de mujeres con las piernas en posición sugerente. Bratton (2011: 34-35) afirma que este material erótico no solo resultaba atractivo para la juventud masculina de clase media-alta, sino que además, fascinaba a un gran número de chicas del mismo estatus.

Especialmente relevante es el trabajo de Janice Norwood (2017), quien examina la representación visual de Eliza Vestris (1797-1856) y de Sara Lane (1822-1899) en retratos que circulaban entre su público e incluso entre entornos privados masculinos. A propósito, el ejemplo de Eliza Vestris -comúnmente conocida como Madame Vestris- es muy similar al de Priscilla Horton. Ambas gozaron de la atención del público durante sus primeros años como actrices, siendo recordadas principalmente por su imagen -especialmente por sus piernas. Vestris es bautizada por sus contemporáneos como «las mejores piernas del siglo» (Bratton, 2011: 72) mientras que al nombre de Priscilla Horton -incluso durante sus posteriores años como Mrs. German Reed-solía acompañarle la descriptiva «the nymph with the golden locks» (Bow Bells, 1866: 41) o la ninfa de cabellos dorados. Esto demuestra que las actrices de la época eran valoradas por su estética -aunque su buena imagen no siempre podía salvarlas de críticas devastadoras. Sobre el escenario, las mujeres se tornaban seres sobrenaturales -como en el caso de Priscilla Horton, apodada de ninfa. Los hombres -la esfera pública que se encargaba de juzgarlas- clasificaban a las actrices de «hechiceras», «sirenas» e incluso de «panteras», ya que no creían que una mujer común fuera capaz de ejercer tal poder sobre ellos (Powell, 1997: 10-14).

En este artículo seguimos los pasos de Priscilla Horton en su ascenso en el mundo teatral del Londres victoriano. Su vida nos sirve de marco en el cual podemos dar cabida a la situación de las mujeres en general y de las actrices en particular en un siglo repleto de cambios; un siglo en el que las mujeres se atrevieron a cruzar los límites impuestos sobre ellas, recuperando así la agencia sobre sus propios cuerpos y su identidad $^{8}$. Con el propósito de seguir un orden cronológico en la vida de Priscilla Horton, la siguiente sección examina sus primeros años como actriz a partir de 1828. Los inicios de su carrera nos muestran cómo la identidad de una actriz podía quedar marcada desde temprana edad, dejando una imagen muy concreta en las mentes del público.

En la tercera sección de este estudio veremos cómo el matrimonio muchas veces se presentaba como herramienta de reforma de la actriz. Su retirada de los escenarios era, casi siempre, provocada por su regreso a la esfera privada del hogar marital y a la familia. Sin embargo, en esta sección explicaremos cómo Priscilla Horton, tras su matrimonio y transformación en Mrs. German Reed, consiguió no

8 Clúa Ginés (2007: 157-172) explica cómo las performers femeninas que surgieron a finales del siglo XIX aprovecharon su exposición pública para reconfigurarse y construir sus identidades de forma subversiva, tanto dentro como fuera de los escenarios. 
solo no apartarse de los escenarios, sino que además persuadió a un público selecto de que sus gustos e imagen se habían elevado. Junto con su marido, Horton impulsó un nuevo género teatral en el panorama londinense: el «entretenimiento de salón» o drawing-room entertainment. Sus «entretenimientos», como los mismos Reed calificaban a sus actuaciones, engañan al espectador y crean un falso entorno de privacidad en su teatro. Esto se conseguía a través de una escena muy cuidada, en la que los Reed contaban historias en lo que parecía su propio salón familiar.

Finalmente, resumiremos los puntos más relevantes de esta investigación y reafirmaremos la figura de Priscilla Horton como ejemplo destacable de la capacidad de muchas actrices decimonónicas para transformarse bajo el escrutinio de toda una ciudad. Ella, al igual que muchas otras, recuperó la agencia sobre su cuerpo y logró pasar de ser un simple par de piernas a dirigir uno de los recintos teatrales más importantes del West End londinense.

\title{
2. La reputación de la actriz como objeto erótico y sobrenatural
}

Priscilla Horton comenzó su carrera como actriz en 1828 en el teatro Surrey de Londres, cuando apenas contaba con diez años de edad. En una reseña biográfica sobre Horton, la revista Bow Bells (1866) relata cómo fue apadrinada e instruida por Sir George Smart, uno de los principales músicos y directores de orquesta de la Inglaterra decimonónica. La influencia de éste en Londres, específicamente en el teatro Covent Garden, propició la entrada de Horton en el coro femenino del establecimiento. Según Bow Bells, durante su tiempo como corista o chorus girl, Horton desarrolló su talento y ganó fuerza sobre el escenario. Sin embargo, las escenas de coristas o ballet girls eran conocidas popularmente como «escenas de piernas» o leg scenes ${ }^{9}$. Así, el papel de ballet girl o corista implicaba una sexualización del cuerpo femenino sobre los escenarios. Tal sexualización contradice las reglas morales y sociales de la época, según las que la modestia y el decoro constituían rasgos imprescindibles en una mujer. Esta situación era expuesta de forma satírica en las revistas contemporáneas, como en el ejemplo de «The humble apology of Grace Tarleton, a poor ballet girl», que apareció en Judy en 1869. Las líneas de disculpa de la ficticia Grace Tarleton simbolizan la doble moral por la que las actrices eran juzgadas: si llevaban ropas reveladoras era porque el público así lo exigía. En su apología, Tarleton justifica sus vestimentas y manierismos sobre el escenario y acusa al público que tanto las critica de hipócritas:

\author{
[...] Methinks it is unjust and false \\ To brand us all as vicious; \\ We ballet-girls and our costumes \\ Are what the public wish us! \\ Why should to dance, for bread, 'in tights' \\ So scandalize beholders
}

9 En la revista The Dark Blue, Thomas Hood (1871: 114-118) escribe sobre los gustos del público en cuanto a comedia, escenas con actrices vistiendo medias ajustadas y la sobreactuación típica de la pantomima y el teatro burlesco de la época. 
Who vie, from choice, in showing off

A great deal more than shoulders $(J u d y, 1869)^{10}$.

El público, por lo tanto, pedía mujeres en ropas reveladoras sobre el escenario, aunque no dudaba en etiquetarlas como inmorales e incluso como prostitutas ${ }^{11}$. Según la moralidad victoriana, las mujeres debían permanecer sumisas al hombre y en la esfera privada del hogar; así, las actrices desafiaban la regla impuesta sobre ellas $y$, sobre el escenario, se transformaban en panteras o seres sobrenaturales capaces de capturar las mentes y la atención de los hombres que iban a verlas.

Kerry Powell (1997) explica cómo los hombres de la Inglaterra del xIX usaron a la actriz como elemento de opresión para las mujeres corrientes. En artículos, novelas y obras de teatro, los autores convertían a la actriz en un ejemplo de maldad y vicio, haciendo énfasis en su singularidad y diferenciándola de las féminas victorianas corrientes. En la ficción, los personajes femeninos que se dedicaban al teatro solían encontrar un destino fatídico ${ }^{12}$. Hay algunas excepciones, especialmente en aquellos textos escritos por mujeres. Florence Nightingale defiende en Cassandra (1854) que las féminas de la época aspiraban a convertirse en actrices porque reconocían en ese trabajo un esfuerzo y una mejora que deseaban en su vida; ser actriz, para muchas, suponía no cumplir las expectativas impuestas sobre ellas y alcanzar el desarrollo personal y profesional que tanto ansiaban.

Esta prosperidad se hace realidad en el caso de Priscilla Horton, quien después de su experiencia como corista en el Covent Garden, continúa su carrera apareciendo en papeles secundarios en dos de los teatros más importantes de Londres: el Victoria y el Strand. Sin embargo, es en 1838 cuando interpreta en Covent Garden el papel por el que luego sería reconocida en la metrópolis: Ariel, sílfide sirviente de Próspero en La tempestad (1611) de William Shakespeare ${ }^{13}$. A pesar de que Ariel en el original

10 Las traducciones de citas son propias: «Creo que es injusto y erróneo / etiquetarnos a todas de depravadas; / ¡nosotras, las bailarinas, y nuestros trajes / somos lo que el público desea! / ¿Por qué bailar en leotardos para poder comer / escandaliza tanto a los espectadores, / quienes compiten, por elección propia, en exhibir / mucho más que los hombros?»

11 Especialmente a principios del siglo xIx, la prostitución era asociada al teatro ya que era habitual encontrar a prostitutas en los pasillos oscuros de los auditorios de los principales teatros -entre ellos, el Covent Garden y el Drury Lane. Además, Michael Booth (1991: 64) añade que también se congregaban a las puertas de los teatros -tanto en el East como en el West End. Por esta razón, además de por muchas otras, las mujeres «respetables» no solían ir a ver las representaciones solas.

12 Entre las obras más aclamadas por el público londinense se encuentra Life of an Actress (1862) de Dion Boucicault. En ella, se muestran dos tipos claros de mujeres dedicadas al teatro: la actriz veterana, de moral laxa y acostumbrada a ser adulada por hombres de altos rangos y la actriz novel, quien se da cuenta en su primera actuación ante un público de los vicios y perfidias que el mundo del espectáculo conlleva. Posteriormente y con el movimiento de la New Woman a finales de siglo xIX y principios del xx, los dramaturgos cuentan historias de actrices que abandonan a sus maridos para no convertirse en «animales domesticados»-como en el caso de Connie, the Actress (1902) de John Strange Winter.

13 La obra en cuestión se titulaba igual que la original, y fue interpretada el 13 de Octubre de 1838. Dirigida por el famoso William Macready (1793-1873) durante su gerencia en el Covent Garden, la obra incluía un espectacular panorama representando el naufragio de la primera escena (Summers, 1966: LVIII). 
shakespeariano es notablemente clasificado de «él», el teatro victoriano continuamente utilizaba a mujeres en sus adaptaciones y reinterpretaciones -ataviadas de reveladores trajes que dejaban ver sus piernas. En cambio, el personaje de Ariel sirve de vehículo para que la actriz -y, en definitiva, las mujeres- demuestre su capacidad de ser un cuerpo activo, "volando» sobre el escenario y eclipsando a la verdadera protagonista de la obra, Miranda, quien acababa por acatar las normas de su padre, Próspero, y no se desvía de la sumisión esperada ${ }^{14}$. Horton, en su papel como Ariel, capturó la atención del público y se meció sobre ellos suspendida por cables que creaban la ilusión de su vuelo. Quizá en este momento, Horton se convirtió en la ninfa de mejillas sonrosadas que todos recordarían incluso durante sus últimos años ${ }^{15}$.

Horton continuó cosechando éxitos con sus interpretaciones de personajes femeninos shakespearianos, siempre bajo el patrocinio de William Macready, un famoso actor reconvertido en gerente de teatro con propensión a la adaptación de los clásicos de Shakespeare. Con su apoyo, Horton interpretó a Ophelia en Hamlet (Covent Garden, marzo 1840), por lo que fue alabada por los críticos de The Examiner y del Morning Post. Como nota incidental pero representativa de las expectativas de la crítica sobre las actrices, cabe destacar la opinión del periódico The Examiner. En su crítica sobre el papel de Horton como Ophelia, el autor parecía sorprenderse de que una mujer hubiera sido capaz de leer la obra en su totalidad y, además, de haber entendido las connotaciones del papel (Gänzl, 2018: 310).

Siguiendo a Macready, Horton interpretó el papel de Acis en la ópera Acis and Galatea (1841) en el Drury Lane. Este supuso su primer breeches role, es decir, su primer papel en el que apareció travestida sobre el escenario. Al interpretar al héroe protagonista, era común que las actrices victorianas actuaran con ropas masculinas, especialmente en las obras pantomímicas y burlescas. Jacky Bratton afirma que durante la primera mitad del siglo XIX, los papeles travestidos se debían en parte a la popularidad de los bailes de máscaras, los cuales eran muchas veces «en travesti» (Bratton, 2011: 119). Así pues, el teatro victoriano vio un auge en mujeres interpretando papeles masculinos, aunque siempre manteniendo ciertos atributos femeninos -entre ellos, los más comunes: bustos voluptuosos, muslos y piernas contorneadas y manos y pies pequeños y delicados (Shaw y Ardener, 2005: 14). No se pretendía engañar a nadie, ya que el público sabía de sobra que una mujer interpretaba al héroe masculino ${ }^{16}$.

14 Marjorie Garber (2008: 18-20) examina las adaptaciones de Shakespeare a lo largo del siglo xIx y ofrece una visión del personaje de Ariel, equiparándolo a los personajes de hadas o seres sobrenaturales femeninos de los escenarios victorianos.

15 Una de las imágenes que perduran de Priscilla Horton es su retrato como Ariel realizado por Daniel Maclise (1806-1870) en 1838. En este, destaca su piel pálida y su sonrisa traviesa. Ataviada de un revelador vestido amarillo, sus hombros, brazos y piernas quedan al descubierto. Más conservadora es la ilustración de H. Johnston realizada el mismo año y publicada por McLean \& Haes. En este caso, su traje blanco es más discreto y sus brazos y piernas se muestran más cubiertas.

16 El impacto de los breeches roles se reflejaba en la crítica impresa incluso desde principios de siglo. Las revistas incluían notas biográficas de actrices con asiduidad, las cuales no siempre gustaban a sus lectores. Por ejemplo, The Lady's Monthly Museum se vio cuestionado en su decisión de incluir una reseña biográfica de la actriz Dora Jordan en 1805, cuando un lector les escribió una carta de querella por considerar que dicha actriz no era digna de servir de ejemplo para sus lectoras. Esto, según él, se debía a su propensión a actuar en papeles «indecentes» en los que debía ir travestida (W. J., 1805: 191). 
Quizá, como afirma Ellen Donkin, los autores creaban estos papeles para satisfacer su propio deseo de observar a mujeres en posición reveladora sobre los escenarios (Davis y Donkin, 1999: 63). A pesar de ello, estas actrices a menudo eran consideradas sexless (Powell, 1997: 30) o asexuadas, censuradas de irracionales y poco femeninas ${ }^{17}$. Sin embargo, no se puede negar que el intercambio de roles $-y$ de identidad-, le permitía a las mujeres reafirmar su autoridad y, en definitiva, ser tomadas en consideración por sus contemporáneos ${ }^{18}$. Así, una mujer desempeñando un breeches role, era capaz de formar parte activa de la narrativa, siendo ella la viajera, guerrera o exterminadora de dragones.

\section{La transformación de la actriz: de Priscilla Horton a Mrs. German Reed}

Hasta ahora, hemos visto cómo la reputación de una actriz podía ayudarle en su carrera y en el desarrollo de su vida privada. Gozar de la aprobación de la crítica, tanto por sus talentos como por su moralidad, le daba una credibilidad sobre los escenarios que influía irremediablemente en su popularidad entre el público. Para ello, se insistía en humanizar a la actriz, hacerla accesible a la gente corriente. Esto se realizaba casi siempre mediante retratos en los que se la presentaba fuera del ámbito teatral -es decir, sin vestuario ni maquillaje ${ }^{19}$. En su estudio, Janice Norwood (2017) observa las diferentes versiones que existían de las actrices: en ocasiones, capturadas en plena representación, con actitudes activas y vestidas como su personaje; en otras, en posturas pasivas que apenas denotan expresión ni voluntad personal, con trajes modestos en el entorno familiar. Esta dualidad siempre presente al referirse a las actrices tenía que ver con la naturaleza de su trabajo. Ellas se dedicaban a expresar emociones y mostrarse pasionales cuando sus contemporáneas fuera de los escenarios eran instadas a disimularlas ${ }^{20}$. Una de las herramientas para humanizar a la actriz y quizá rebajar su amenaza era el matrimonio. Estas uniones, casi siempre, se realizaban con miembros del entorno teatral, ya fuera músicos, directores, gerentes, o incluso escritores. Mediante el matrimonio, culminaba la contradicción personal de la actriz: era personaje público sobre el escenario, donde se mostraba independiente y fuerte, pero también era un personaje privado en el entorno del hogar, donde actuaba como esposa y madre.

17 Esta censura se repite incluso a finales del siglo xIx, cuando el surgimiento de la New Woman y del dandy subvirtieron los roles de género en Inglaterra. Notablemente, el libro Degeneration escrito por Max Nordau y publicado en Inglaterra en 1895, hace hincapié en la pérdida del género en hombres -quienes, en su opinión, empezaron a feminizarse- y en mujeres -que cada vez eran más «masculinas».

18 Anna Clark (1995: 64) explica cómo los periódicos satíricos de la era victoriana adoptaron el término breeches y lo convirtieron en «the struggle for the breeches». Este «forcejeo por los pantalones» simbolizó la lucha de las mujeres de la época por conseguir los mismos derechos que sus maridos en el matrimonio y su protesta por los continuos casos de violencia doméstica en los que el hombre no era culpabilizado.

19 Especialmente desde el siglo xviII, se buscaba «domesticar la sexualidad de las actrices» (Straub, 1992: 94).

20 Kerry Powell (1999: 35) habla de la actriz como madwoman o loca, debido a su capacidad para expresar sentimientos que, fuera de los escenarios, eran considerados histeria femenina. 
Fue mediante el matrimonio que Priscilla Horton se reafirmó como actriz y pionera del siglo xIx por excelencia. En 1844, se casó con Thomas German Reed, el aclamado director de orquesta del teatro Haymarket. Unos años después, en 1855, juntos crearon sus propias obras siguiendo el estilo del drawing-room entertainment o entretenimiento de salón. En sus primeras interpretaciones, los Reed llamaron a su entertainment «Illustrative Gatherings»; es decir, reuniones ilustrativas. Durante estas reuniones iniciales, Mr. German Reed se sentaba al piano y acompañaba musicalmente la interpretación de su esposa. Así, Horton -ahora Mrs. German Reedera la encargada de narrar historias y ejemplificar pequeños sketches describiendo eventos y personas que bien podían ser reales. En realidad, era ella la principal atracción para el público, ya que incluso el título empleado para publicitar sus actuaciones era «Miss P Horton's Illustrative Gatherings» (Gänzl, 2018: 314).

Después de sus primeros pasos juntos realizando estos entretenimientos en otros locales como el St. Martin's Hall de Londres, Horton siguió actuando por su cuenta en conciertos de E. W. Thomas en el Philharmonic Hall de Liverpool y realizando lecturas con canciones de varias obras de Shakespeare. Como matrimonio, los Reed se aseguraron el éxito entre las clases media-altas de Londres cuando, en 1856, inauguraron sus entretenimientos en un recinto en el corazón de Regent Street llamado Gallery of Illustration. Esta galería fue construida por John Nash en 1824 para uso privado, pero hasta mitad del siglo XIX se convirtió en un lugar en el que se exhibían ilustraciones panorámicas y dioramas ${ }^{21}$. A menudo, un orador acompañaba a los panoramas y se encargaba de explicar la historia detrás de la ilustración. Sin embargo, no fue hasta 1850 aproximadamente que se permitieron las representaciones musicales y de danza en la Gallery of Illustration, que nunca fue considerado un teatro. Este detalle fue lo que les permitió a los Reed atraer a un público que tachaba a los teatros tradicionales de inmorales. Mediante la meticulosa elección de sus palabras, los Reed se ganaron el patrocinio de un sector selecto de la población londinense.

En gran parte, el éxito de los Reed se debió a la misma Horton, que ya se había labrado una reputación entre el público. Así, los carteles publicitarios de los entretenimientos de Mr. y Mrs. German Reed, seguían incluyendo el nombre de soltera de Horton, además de su famoso apodo «the nymph with the golden locks», según la revista Bow Bells (1866: 41). Esto, además del elevado protagonismo que Horton tenía en sus actuaciones con su marido, nos lleva a creer que ella había recuperado el control de su imagen y su identidad. Como Mrs. German Reed, Horton se estableció como una señora de gustos refinados y talento para el espectáculo y la música. Mediante sus entretenimientos en la Gallery of Illustration, había dejado de ser una marioneta y se había transformado en marionetista. En su nota biográ-

21 Entre los muchos panoramas que se exhibieron en el Gallery of Illustration se encuentran Diorama of our Native Land, Illustrative of England and its Seasons de Grieve, Telbin, Jones, Absolon y Herring y Events of the War de Grieve y Telbin. A este último panorama le acompañaba el orador J. H. Stocqueler, quien utilizó diagramas para explicar los detalles de la zona de combate exhibida. En general, los panoramas y dioramas solían fomentar el patriotismo y enseñaban los nuevos avances del Imperio Británico (Huhtamo, 2013: 197). 
fica realizada por Bow Bells, se remarcaban sus habilidades: «Mrs. Reed is a good linguist (self-taught), writes charming verses, composes songs, and takes very striking likeness; and, above all, her memory is most extraordinary ${ }^{22} \gg$ (Bow Bells, 1866: 41). El mensaje queda claro: ella es el verdadero prodigio en la alianza entre Mr. y Mrs. German Reed.

Como hemos comentado con anterioridad, en muchos sentidos el ejemplo de Priscilla Horton reconvertida en Mrs. German Reed se asemeja al de su predecesora Eliza Vestris. Madame Vestris, afamada por sus piernas y por un erotismo que supo explotar, llegó a ser la gerente de teatros tan importantes como el Olympic -desde 1830 a 1839-, el Covent Garden -desde 1839 a 1842- y el Lyceum -de 1847 a 1855. Vestris, en sus años como gerente, sacó ventaja de su reputación y patrocinó el teatro burlesco, un género famoso por su erotismo, fantasía, diálogos ingeniosos y dobles sentidos. En el caso de Priscilla Horton, con sus entretenimientos supo transformarse en lo que el público esperaba de ella: ahora era una señora casada cuyo dominio era el ámbito privado. La principal herramienta de la que se hizo servir era los decorados en sus entretenimientos. En la Gallery of Illustration -que podía dar cabida hasta a quinientas personas-, el público tenía la sensación de estar en la misma sala de estar o salón privado de los Reed. En otras ocasiones, la escena reproducía su alcoba privada o la zona común de un hotel. Así, los espectadores sentían que eran parte de la historia, o mejor dicho, que formaban parte de la vida privada del matrimonio Reed (Bratton, 2011: 76). En definitiva, la percepción del público había cambiado al verla junto a su marido -que la acompañaba al piano mientras ambos relataban historias.

Durante sus entretenimientos e ilustraciones, Horton solía interpretar los papeles más complejos. Mientras contaban anécdotas a su público -o, según les hacían creer, a sus invitados-, Horton iba cambiando de vestuario para ilustrar así de manera fiel a los personajes de los que iban hablando. Por ejemplo, en su actuación titulada Popular Illustrations from Real Life realizada el 24 de diciembre de 1860, Mr. Reed se encuentra a un pobre chico italiano que le relata de forma amena su viaje a pie desde Génova a Inglaterra. Este muchacho es interpretado por Horton, quien está acostumbrada ya y ha sido aclamada anteriormente por sus papeles travestidos. Llama la atención la facilidad y naturalidad con la que Horton es capaz de interpretar personajes masculinos sobre el escenario con su marido -lo cual hace a menudo en sus ilustraciones-, esta vez ante un público que quizá se escandalizaría al presenciar lo mismo en otro establecimiento de la ciudad. Sin embargo, la facilidad de travestismo en sus papeles se presenta como arma de doble filo, ya que muestra una vez más, la capacidad de las mujeres para ser versátiles y, a su vez, falsas (Bratton, 2011: 77).

En cuanto a los diálogos que los Reed interpretaban, no está del todo claro quién los escribía en sus inicios -aunque, tal y como sugieren las críticas y reseñas biográficas, lo más probable es que fuera Horton la encargada de hacerlo debido a su ex-

22 Las traducciones de citas son propias: «La señora Reed es una buena lingüista (auto-didacta), escribe versos maravillosos, compone canciones y se caracteriza de manera impresionante; y sobre todo, su memoria es extraordinaria». 
periencia como oradora y su perfecta articulación. Más tarde, cuando ya se habían asentado en sus ilustraciones, los Reed emplearon a escritores reconocidos por el público victoriano -entre ellos, William Brough y Mark Lemon, conocidos por su ingenio y crítica social. Sea como fuere, en sus ilustraciones, Horton hacía gala de su apoyo a la lucha por los derechos de las mujeres. En el entertainment que hemos mencionado previamente, Popular Illustrations from Real Life (1860), Mrs. Reed recita las siguientes líneas:

MRS. REED: [...] like all the rest of the men they fancy that we poor women are mere shuttlecocks to be knocked about just as their fancy suits them. [...] Oh, I am the quietest little woman in the world, but I cannot bear such treatment, I can't indeed, and I don't believe that any woman of spirit ever could.

(Song) Men tell us 'tis fit that wives should submit

To their husbands submissively meekly

That whatever they say, their wives should obey

Unquestioning, stupidly, weakly

Our husbands would make us their own dictum take

Without ever a wherefore or why for it

But I don't, and I can't, and I won't, and I shan't

No, I will speak my mind if I die for it (Mr. \& Mrs. Reed, 1860: 49) ${ }^{23}$.

En su monólogo y canción, Horton critica el rol sumiso de la mujer casada, haciendo hincapié en que ninguna «mujer fuerte» o woman of spirit debería soportar los caprichos de su marido. Así, según su canción, las esposas no deberían aceptar con sumisión las órdenes de sus maridos, sino que deberían hacerse oír y hablar con franqueza aunque su vida dependiera de ello. Este mensaje contrasta con la descripción que Bow Bells da sobre la misma Priscilla Horton, ya como mujer casada en 1866:

[...] in private life, [Horton] has so unassuming and quiet a manner, that a stranger would not for a moment suspect she was a member of a profession to which fame has attributed a quantum suff of natural assurance as a requisite; far less that she was the gay, off-hand actress [...] or the wild, spirit-like, sweet singer (Bow Bells, 1866: 41) ${ }^{24}$.

Esta descripción encaja con las fotografías que se realizaron de Horton una vez casada: entre otras, una la muestra sentada junto a un escritorio, con el cuerpo com-

23 Las traducciones de citas son propias: «[...] como el resto de hombres, se creen que nosotras, pobres mujeres, no somos más que volantes que golpear a su antojo [...] Ah, yo soy la mujer más reservada del mundo, pero no puedo soportar tal trato, no puedo, y no creo que ninguna mujer de carácter pueda hacerlo. / (Canción) / Los hombres nos dicen que las esposas deben someterse / a sus maridos dócil y mansamente. / Que cualquier cosa que digan, las esposas han de obedecer / ciega, estúpida y débilmente. / Nuestros maridos querrían que siguiéramos sus dictámenes / sin un «ipor qué?» / Pero no, no puedo, no lo haré, / no, yo diré mi opinión aunque muera por ello».

24 Las traducciones de citas son propias: «[...] en su vida privada, [Horton] tiene un carácter tan modesto y reservado que un extraño no sospecharía ni por un momento que es miembro de una profesión afamada de tener como prerrequisito el descaro; y mucho menos sospecharía que es la actriz alegre y casual $[\ldots]$ o la cantante dulce, salvaje y sobrenatural». 
pletamente cubierto por un vestido oscuro con crinolina y el pelo recogido ${ }^{25}$. Esa era ella fuera de los escenarios; la domesticación de la actriz había sido completada o, al menos, eso parecía. Según Linda M. Shires, algunas mujeres que participaban en el entorno público del siglo XIX adoptaron una rigurosa rectitud moral para evitar así la censura social (Fraser, Green y Johnston, 2003: 149). Además de esto, y tal y como Michael Goron (2016) propone, el cambio de identidad de Priscilla Horton a Mrs. German Reed fue motivado por la necesidad de los Reed de seguir contando con el apoyo del público incluso cuando la belleza característica de ella -que tantos éxitos le había otorgado- empezó a esfumarse en su mediana edad.

En definitiva, la transformación de Priscilla Horton al final de su carrera le permitió convertirse en un modelo de modestia y moralidad, abandonando en cierta medida el mundo del espectáculo de moral dudosa -no más leg scenes-, y dándole la oportunidad de verbalizar las inquietudes de todo un grupo de mujeres ante la élite londinense. Así, y bajo el lema de «entretenimiento», Priscilla Horton divulgó, junto a su marido, los temas sociales más relevantes y polémicos de su tiempo.

\section{Conclusiones}

Cuando Priscilla Horton falleció en marzo de 1895 después de haber quedado viuda, los obituarios de los periódicos ingleses seguían haciendo mención a su papel como Ariel en La tempestad (1838) a cargo de William Macready ${ }^{26}$. Los que la habían visto crecer sobre los escenarios, ahora ellos mismos también de edad avanzada, irremediablemente recordarían a la «ninfa de cabellos dorados» que tanto se publicitaba en posters y carteleras en su juventud. Las imágenes representando a Horton en su papel de Ariel, además de otras ilustraciones en las que destacaba su piel pálida, manos y pies pequeños y mejillas sonrosadas, habían dejado huella en su reputación como actriz y, en definitiva, como mujer.

Tal y como se ha mencionado con anterioridad, la imagen pública de una actriz ejercía un poder decisivo sobre su carrera. En este artículo hemos visto cómo, a menudo, las mujeres eran reducidas a meras partes de su cuerpo, siendo desasociadas de su identidad como ser humano. Así, las famosas leg-scenes en las que se exhibía en fila a un gran número de bailarinas en trajes ajustados, satisfacían un apetito por lo erótico y el público se tornaba voyeur. Las relaciones de poder entre actriz y espectador son recíprocas: mientras que la actriz es comparada con un ser sobrenatural capaz de capturar las mentes de todo aquel que la ve sobre los escenarios, el espectador puede reducirla a un par de piernas o, en definitiva, en un objeto de autosatisfacción. A pesar de ello, hemos visto cómo el mundo del teatro se convertía en un espacio de liberación para las mujeres, proporcionándole una independencia no alcanzable en la esfera privada del hogar; actuar, en muchas ocasiones, suponía tomar posesión de sus propios cuerpos.

Entre los elementos liberadores del teatro, hemos visto los breeches roles, mediante los cuales la actriz travestida tomaba el poder de la obra y se convertía en

25 La fotografía en cuestión se trata de una carte-de-visite y fue realizada alrededor de 1860 por Henry Squire \& Co. 26 Este es el caso del Illustrated Sporting and Dramatic News (23 marzo 1895: 10).

AsPARKÍA, 33; 2018, 261-275 - ISSN: 1132-8231 - DOI: HTTP://DX.DOI.oRg/10.6035/AsPARKIA.2018.33.15 
protagonista. Estos papeles podían significar la desacreditación de una actriz si ésta recurría demasiado a ellos, ya que podía intensificarse la sensación de poca feminidad y se la tachaba de degenerada ${ }^{27}$. En el caso de Priscilla Horton, quien siempre mantuvo una imagen muy atractiva para el público, quizá el matrimonio con Thomas German Reed le hizo establecerse como mujer casada por encima de actriz. Por este motivo, el matrimonio se torna herramienta de domesticación de la actriz, haciendo a menudo que muchas de ellas se retiren a las bambalinas para dedicarse a la gerencia del teatro o incluso al hogar familiar. Sin embargo, como se ha mencionado previamente, Priscilla Horton consiguió lidiar con el proceso de cambio de mujer pública a mujer privada gracias a su ingenio en el desarrollo de los entertainments.

Ya como Mr. y Mrs. German Reed, la elección del local The Gallery of Illustration les permitió aproximarse a un público que los tendría en alta estima por sus gustos estéticos y su relación conyugal completamente adecuada a ojos de todos. De alguna manera, parece que Horton supo asumir en apariencia un rol secundario al de su marido, a pesar de ser ella la que llevara todo el peso de las interpretaciones, memorizara monólogos larguísimos y se esforzara por caracterizarse de acuerdo a sus personajes. Ya como Mrs. German Reed, siguió trabajando de la misma manera que antes -aún asumía papeles en los que debía travestirse y cantaba canciones populares; sin embargo, algo había cambiado en la percepción del público. Sus breeches roles ya no eran pecaminosos y ahora tenía la libertad de recitar versos que alentaban la emancipación de las mujeres e iban en contra de la sumisión conyugal. Todo esto, en definitiva, se vio propiciado por su nuevo estatus como mujer casada, una herramienta que supo utilizar a su favor. Dejando atrás su persona pública de actriz, Priscilla Horton fomentó la sensación de cercanía al público en sus actuaciones; quienes, más que ejercer de espectadores, sentían estar en el hogar familiar de un matrimonio perfectamente privado.

\section{REFERENCIAS BIBLIOGRÁFICAS}

Anón (1866). «Mrs. German Reed» en Bow Bells, a magazine of General Literature and Art, for family reading, agosto 1866, p. 41.

ANón (1869). «The humble apology of Grace Tarleton, a poor ballet girl» en Judy, or the London Serio-Comic Journal, 10 febrero 1869, p. 167.

Anón (1895). «The German Reed Entertainment» en Illustrated Sporting and Dramatic News, 23 de marzo de 1895, p. 10.

27 Marshall (1998: 95) explica cómo, con la inmersión de la mujer en la esfera pública gracias a plataformas como el teatro y el activismo político, los críticos de mediados y finales de siglo advirtieron sobre la «muerte» de la belleza y la feminidad. Esta decadencia la atribuyeron a las nuevas ocupaciones de las mujeres fuera del ámbito doméstico. Además, a finales de siglo, Richard von Kraft-Ebing diagnosticó de «instinto homosexual» el travestismo de las actrices sobre los escenarios (Powell, 1997: 35). 
Bоотн, Michael R. (1991). Theatre in the Victorian Age, Cambridge: Cambridge University Press.

BRATtON, Jacky (2011). The Making of the West End Stage: Marriage, Management and the Mapping of Gender in London, 1830-1870, Cambridge: Cambridge University Press.

ClarK, Anna (1995). The Struggle for the Breeches. Gender and the Making of the British Working Class, Berkeley and Los Angeles: University of California Press.

Clark, Linda L. (2008). Women and Achievement in Nineteenth-century Europe, Cambridge: Cambridge University Press.

CLÚA GINÉs, Isabel (2007). «El cuerpo como escenario: actrices e histéricas en el finde-siècle» en Dossiers Feministes, №10, pp. 157-172.

Davis, Tracy C. (2000). The Economics of the British Stage 1800-1914, Cambridge: Cambridge University Press.

Davis, Tracy C. y Ellen Donkin (eds.) (1999). Women and Playwriting in Nineteenthcentury Britain, Cambridge: Cambridge University Press.

Fraser, Hilary, Green, Stephanie y Judith Johnston (2003). Gender and the Victorian Periodical. Cambridge: Cambridge University Press.

GäNZL, Kurt (2018). Victorian Vocalists, New York: Routledge.

GARBER, Marjorie (2008). Shakespeare and Modern Culture, New York: Pantheon Books.

Goron, Michael (2016). Gilbert and Sullivan's 'Respectable Capers'. Class, respectability and the Savoy Operas, 1877-1909, London: Palgrave Macmillan.

Hood, Thomas (1871). «In town» en The Dark Blue, Vol. 1, Nº1, pp. 114-118.

Huntamo, Erkki (2013). Illusions in Motion: Media Archeology of the Moving Panorama and Related Spectacles, Cambridge: The MIT Press.

Levine, Philippa (1987). Victorian Feminism, 1850-1900, Tallahassee: Florida State University Press.

Marshall, Gail (1998). Actresses on the Victorian stage: feminine performance and the Galatea myth, Cambridge: Cambridge University Press.

Nordau, Max (1895). Degeneration, London: Heinemann.

Norwood, Janice (2017). «Picturing Nineteenth-Century Female Theatre Managers: the Iconology of Eliza Vestris and Sara Lane» en New Theatre Quarterly, Vol. 33, $\mathrm{N}^{\circ} 1$, pp. 3-21.

Powell, Kerry (1997). Women and Victorian Theatre, Cambridge: Cambridge University Press.

ReEd, Mr. y Mrs. German (1860). Popular Illustrations from Real Life. Entertainment for performance at the Royal Gallery of Illustration, Regent Street, London. Lord Chamberlain's Catalogue of Plays, British Library manuscripts collection. Add MS 52999 S.

Shanley, Mary Lyndon (1989). Feminism, Marriage and the Law, Princeton: Princeton University Press.

Shaw, Alison y Shirley Ardener (eds.) (2005). Changing Sex and Bending Gender, New York: Berghahn Books.

Straub, Kristina (1992). Sexual Suspects: Eighteenth-Century Players and Sexual Ideology, Princeton: Princeton University Press. 
Summers, Montague (1966). Shakespeare Adaptations. The Tempest, the Mock Tempest, and King Lear, New York: Scholarly Books.

W. J. (1805). «To the editor of the Lady's Museum» en The Lady's Monthly Museum, March 1 ${ }^{\text {st }}$, p. 191.

Recibido el 28 de marzo de 2018

Aceptado el 7 de junio de 2018

BIBLID [1132-8231 (2018): 261-275] 